\title{
Adaptive servoventilation in diastolic heart failure and Cheyne-Stokes respiration
}

\author{
T. Bitter*, N. Westerheide ${ }^{*}$ L. Faber*, D. Hering*, C. Prinz*, C. Langer*, \\ D. Horstkotte* and O. Oldenburg*
}

ABSTRACT: A high prevalence of nocturnal Cheyne-Stokes respiration (CSR) has been documented in patients with heart failure with normal left ventricular ejection fraction (HFNEF). The aim of the present study was to investigate the effects of adaptive servoventilation (ASV) for treatment of CSR in these patients.

In 60 patients with HFNEF, defined according to current European Society of Cardiology guidelines, CSR was documented by polysomnography (apnoea/hypopnoea index (AHI) of $>15$ events $\cdot h^{-1}$ ). ASV treatment was offered to all patients; 21 initially rejected treatment, withdrew from treatment or presented noncompliant during follow-up (controls), whereas ongoing ASV therapy was initiated in 39 patients (ASV group). Echocardiography, cardiopulmonary exercise testing and measurement of $\mathrm{N}$-terminal-pro-brain natriuretic peptide were performed at baseline and follow-up (11.6 \pm 3 months).

ASV therapy led to a significant reduction in AHI, longest apnoea and hypopnoea length, maximum and mean oxygen desaturation by pulse oximetry, percentage of study time with an oxygen saturation of $<\mathbf{9 0 \%}$ and arousal index. In addition, significant positive effects could be confirmed on absolute and predicted peak oxygen consumption, oxygen consumption at the individual aerobic-anaerobic threshold, oxygen pulse, as well as left atrial size, and transmitral flow patterns (mean early diastolic lengthening velocity and the ratio of peak early Doppler mitral inflow velocity to this lengthening velocity).

ASV effectively attenuates CSR in patients with HFNEF and improves heart failure symptoms and cardiac function. Whether or not this is accompanied by an improved prognosis remains to be determined.

KEYWORDS: Heart failure, sleep-disordered breathing

eart failure with normal left ventricular ejection fraction (HFNEF) is a clinical entity that embodies symptoms of heart failure in the presence of preserved systolic function of the left ventricle. In patients aged $\geqslant 60$ yrs, its prevalence reaches that of heart failure with reduced left ventricular ejection fraction (HFREF), and, by the eighth decade, it is more frequent than HFREF. Thus, it is specifically a disease of the older [1]. The main pathophysiological correlate is impaired left ventricular filling, resulting in diastolic dysfunction with increased end-diastolic left ventricular pressure ( $P$ LV,ED), with consequent pulmonary congestion, increased stimulation of pulmonary vagal irritant receptors (J-receptors) and enhanced chemosensitivity of central and peripheral carbon dioxide receptors. This predisposes to respiratory instability, which may cause nocturnal hyperventilation with subsequent decreases in capillary carbon dioxide tension $\left(P_{\mathrm{c}}, \mathrm{CO}_{2}\right)$, a major pathophysiological cause of Cheyne-Stokes respiration (CSR) [2, 3]. In a recent study, it was possible to demonstrate a prevalence of CSR of $\sim 30 \%$ in HFNEF patients [4]. In addition, CSR itself is accompanied by recurrent hypoxaemias and phases of hyperventilation that may lead to several haemodynamic systemic changes and worsen HFNEF.

Adaptive servoventilation (ASV) has been introduced as a novel ventilatory support device in patients with CSR, which, analogous to continuous positive airway pressure (CPAP), increases overnight $P_{\mathrm{c}} \mathrm{CO}_{2}$ [5]. A superiority concerning suppression of hypopnoea and apnoea events in comparison to oxygen, CPAP and bilevel positive airway pressure support has been demonstrated [5-8]. Although the positive effects of CPAP have been well investigated in patients with HFNEF and coexisting obstructive sleep apnoea, [9-12], data on therapeutic approaches in patients with HFNEF and CSR are lacking.

\section{AFFILIATIONS}

*Dept of Cardiology, Heart and Diabetes Center North RhineWestphalia, Ruhr University Bochum, Bad Oeynhausen, and

\#Dept of Business Administration and Economics, University of Bielefeld, Bielefeld, Germany.

CORRESPONDENCE

T. Bitter

Dept of Cardiology Heart and Diabetes Center NRW Ruhr University Bochum Georgstasse 11 D-32545 Bad Oeynhausen Germany

E-mail: akleemeyer@hdz-nrw.de

Received: March 202009 Accepted after revision: Dec 182009 First published online: Dec 232009 
The aim of the present study was the investigation of ASV effects on clinical and functional parameters in patients with HFNEF compared to a control group of patients who rejected therapy for various reasons.

\section{PATIENTS AND METHODS Patients}

A total of 60 patients were included with HFNEF, defined according to current European Society of Cardiology (ESC) guidelines [13], moderate-to-severe CSR, an apnoea/hypopnoea index (AHI) of $>15$ events $\cdot h^{-1}$ and a proportion of CSR of $>50 \%$. All patients had to be in a stable clinical condition and in New York Heart Association (NYHA) class II-III. Prior to inclusion, evidence of diastolic dysfunction was obtained invasively ( $P$ LV,ED of $>20 \mathrm{mmHg}$ ) and patients had to be on stable medication for $\geqslant 4$ weeks. In order to exclude patients with a significant obstructive and/or restrictive pulmonary disease, spirometric testing was performed. Other exclusion criteria were reduced systolic left ventricular function, significant valvular heart disease, a history of sleep-disordered breathing $(\mathrm{SDB})$ or ongoing treatment of SDB, a proportion of CSR of $<50 \%$, evidence of pulmonary disease, hypercapnia $\left(P_{\mathrm{c}, \mathrm{CO}_{2}}\right.$ of $\left.>45 \mathrm{mmHg}\right)$ in capillary blood gas samples, pregnancy and acute coronary syndrome or acute cardiac decompensation.

The present study represents a prospective trial that was initiated in July 2006, lasting until December 2008. All patients included in the study were invited to reattend the sleep laboratory of the Dept of Cardiology (Heart and Diabetes Center North Rhine-Westphalia, Ruhr University Bochum, Bad Oeynhausen, Germany) every 3 months for either measurement of cardiac function (echocardiography, cardiopulmonary exercise testing, measurement of N-terminal-pro-brain natriuretic peptide (NT-proBNP) and blood gas testing) and sleep studies (therapy group) or measurement of cardiac function alone (control group). Individual end-point data from every patient (mean 11.6 \pm 3 months; range 3-24 months) formed the basis of the present study. During follow-up, patients undergoing invasive procedures (e.g. percutaneous coronary intervention) were excluded from the study. Although the ESC does not recommend any specific pharmacological treatment for HFNEF patients [14], patients with changes in heart failure medication (except for dosage changes) were excluded. The study was approved by the local institutional review board of the Ruhr University Bochum.

\section{Sleep studies}

Sleep studies were performed using full in-hospital polysomnography (N7000/S7000; Embla, Munich, Germany). Electroencephalographic data were collected from central and auricular positions according to RECHTSCHAFFEN and KALES [15]. Eye movements, as well as mandibular and tibial muscle efforts, nasal airflow (pressure), chest and abdominal effort, pulse oximetry and body position, were recorded continuously. In addition, patients were observed by video. Analyses were performed using Somnologica Studio $5^{\mathrm{TM}}$ software (Medcare, Embla) and reviewed by two independent SDB specialists not involved in the patients' treatment.

Hypopnoea was defined as a $\geqslant 30 \%$ reduction in airflow in combination with an oxygen desaturation of $>3 \%$ by pulse oximetry. Apnoea was defined as a cessation of airflow for $\geqslant 10 \mathrm{~s}$. There had to be at least three cycles of crescendo and decrescendo change in breathing amplitude and $\geqslant 5$ events $\cdot \mathrm{h}^{-1}$ of central sleep apnoeas or hypopnoeas during sleep for it to be scored as CSR [16]. Automatic data from treatment devices were visualised using ResScan ${ }^{\mathrm{TM}}$ software (ResMed, Martinsried, Germany).

\section{Adaptive servoventilation}

ASV (AutoSet $\mathrm{CS}^{\mathrm{TM}_{2}}$, ResMed) was introduced to 51 patients. ASV represents a bilevel ventilation system with automatic anticyclic adaptation of pressure support. Individual pressure support was introduced during wakefulness under continuous blood pressure monitoring and adjusted according to nocturnal measurements. At therapy introduction, 31 patients were not willing to receive therapy or rejected therapy after an introductory night. In addition, eight patients withdrew from therapy during follow-up due to nonspecific personal reasons ( $n=2$; all within 3 months) or due to lacking compliance (mean daily use of $<4 \mathrm{~h} ; \mathrm{n}=6$; five within 3 months and one within 6 months). For balancing group sizes and due to the fact that lack of compliance with ventilation therapy is associated with poorer outcome in heart failure patients [17], these patients were regarded as untreated, and thus added to the control group. After a follow-up period, 39 patients undergoing ASV therapy and 21 patients without ASV therapy (12 due to nonspecific reasons (e.g. personal lifestyle and sense of shame), five due to mask intolerance and four due to subjective intolerance to positive airway pressure ventilation) were capable of finishing the study. The study flow chart is given in figure 1. In the control group, sleep studies were performed at baseline only.

\section{Echocardiography}

The diameters and dimensions of the left atrium and left ventricle were measured using M-mode following American Society of Echocardiography guidelines [18]. Since multiple echocardiographic parameters are available for assessing diastolic function, a comprehensive approach was used in the present study. Transmitral Doppler flow, supplying peak early (E) and peak atrial Doppler mitral inflow velocity (A), the ratio $\mathrm{E} / \mathrm{A}$ and deceleration time of $\mathrm{E}$ were used as traditional markers, with limited validity due to load dependence. New methods, such as speckle tracking imaging, provide accurate well-validated data regarding diastolic properties and filling pressures of the left ventricle. Using speckle tracking technology offline evaluation, mean early diastolic lengthening velocity $\left(\mathrm{e}^{\prime}\right)$ was obtained from different segments of the mitral annulus in four-, three- and two-chamber view. Left ventricular filling pressure was determined from the ratio $\mathrm{E} / \mathrm{e}^{\prime}$.

\section{Cardiopulmonary exercise testing}

Symptom-limited bicycle cardiopulmonary exercise testing (ZAN Ferraris, Oberthulba, Germany), starting at $10 \mathrm{~W}$ and increasing at $10 \mathrm{~W} \cdot \mathrm{min}^{-1}$, was performed at baseline and during follow-up. Oxygen consumption $\left(V^{\prime} \mathrm{O}_{2}\right)$, carbon dioxide production $\left(V^{\prime} \mathrm{CO}_{2}\right)$, instantaneous expiratory gas concentrations throughout the respiratory cycle and minute ventilation $\left(V^{\prime} \mathrm{E}\right)$ were measured continuously on a breath-by-breath basis. Cardiac frequency and blood pressure (by sphygmomanometer) were measured at rest, during each stage of exercise 


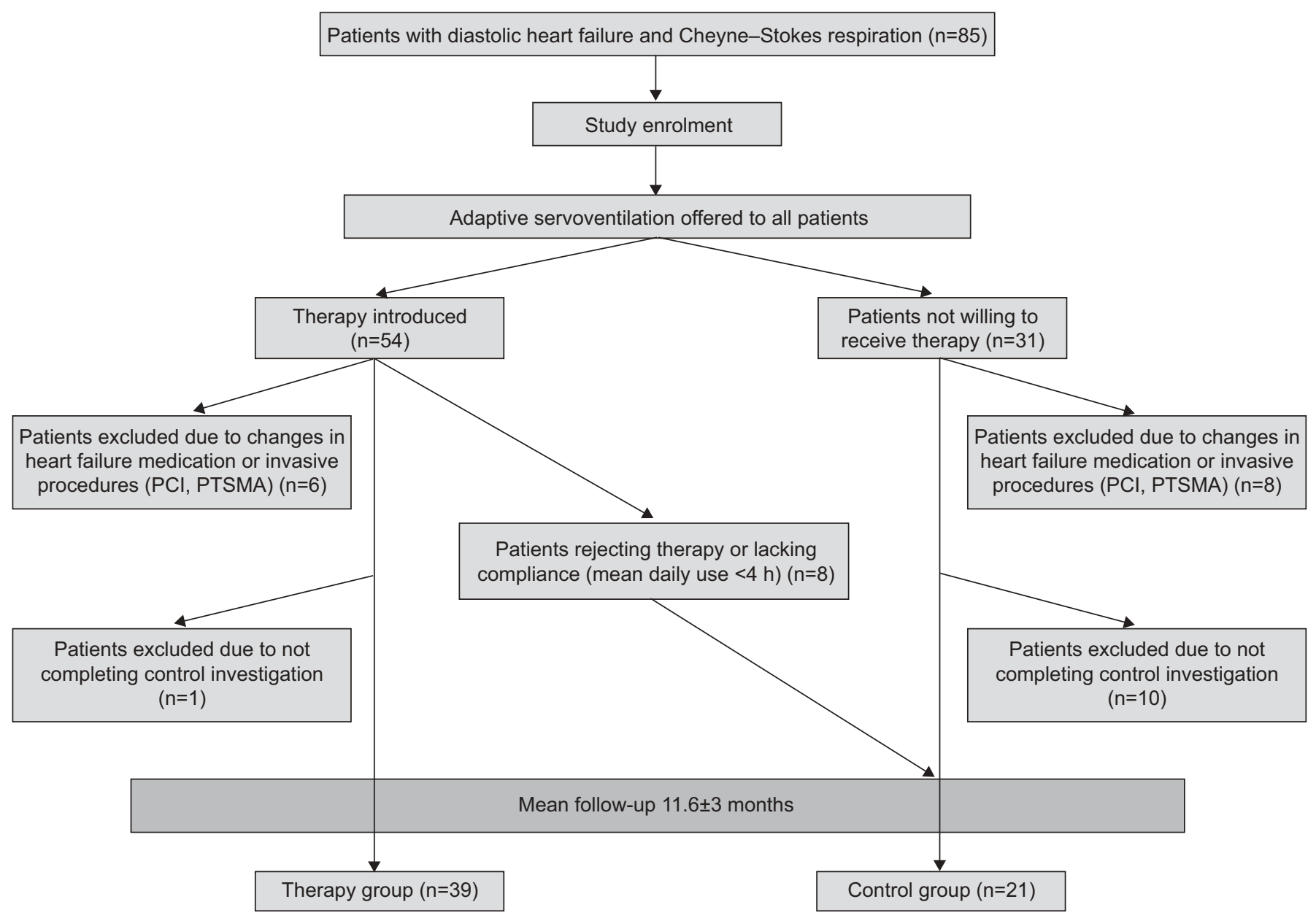

FIGURE 1. Study flow chart. PCI: percutaneous coronary intervention; PTSMA: percutaneous transluminal septal myocardial ablation.

and at peak exercise. Peak $V^{\prime} \mathrm{O}_{2}\left(V^{\prime} \mathrm{O}_{2}\right.$,peak $), V^{\prime} \mathrm{O}_{2}$ at the individual aerobic-anaerobic threshold $\left(V^{\prime} \mathrm{O}_{2}, \mathrm{AT}\right)$ and the ratio $V^{\prime} \mathrm{E} / V^{\prime} \mathrm{CO}_{2}$, as well as maximum workload and total exercise time, were recorded. Predicted $V^{\prime} \mathrm{O}_{2}$, peak was calculated automatically taking the patients' sex and age into account.

$V^{\prime} \mathrm{O}_{2}$, AT was defined as: 1$)$ the point at which the ventilatory equivalent for oxygen $\left(V^{\prime} \mathrm{E} / V^{\prime} \mathrm{O}_{2}\right)$ was minimal and followed by a progressive increase; 2) the point after which the respiratory gas exchange ratio consistently exceeded the resting respiratory gas exchange ratio; and 3) the $V^{\prime} \mathrm{O}_{2}$ after which a nonlinear increase in $V^{\prime} \mathrm{E}$ occurred relative to $V^{\prime} \mathrm{O}_{2}$. $V^{\prime} \mathrm{O}_{2}$,peak was defined as the highest 30-s mean $V^{\prime} \mathrm{O}_{2}$ in the last minute of exercise.

\section{Left heart catheterisation}

Left heart angiography was performed using a 5F pigtail catheter (Cordis, Langenfeld, Germany) for acquisition of the left ventricular ejection fraction and PLV,ED.

\section{Capillary blood gas analysis}

$P_{c}, \mathrm{CO}_{2}$, capillary oxygen tension $\left(P_{\mathrm{c}}, \mathrm{O}_{2}\right)$ and capillary oxygen saturation were measured using an ABL 330 (Radiometer, Copenhagen, Denmark).

\section{N-terminal-pro-brain natriuretic peptide}

NT-proBNP was used as an additional marker of HFNEF severity. Analyses were performed using the Elecsys 2010 analyser (Roche, Basle, Switzerland).

\section{Pulmonary function test}

In order to exclude patients with significant pulmonary disease, a pulmonary function test was performed. Spirometry and body plethysmography were performed with the use of a constantvolume body plethysmograph (ZAN Ferraris). Vital capacity, forced vital capacity, the ratio of forced expiratory volume in $1 \mathrm{~s}$ to forced vital capacity, peak expiratory flow, mid-expiratory flow when 25,50 or $75 \%$ of forced vital capacity remains in the lung, airway resistance, total lung capacity and the ratio of residual volume to total lung capacity were used for the final analysis. The single-breath technique was used for measurement of diffusing capacity for carbon monoxide. For final analysis, the haemoglobin-corrected lung transfer factor for carbon monoxide $(\mathrm{TL}, \mathrm{CO})$ and the carbon monoxide transfer coefficient (or TL,CO/alveolar volume in millimols per minute per kilopascal $(1 \mathrm{kPa}=7.502 \mathrm{mmHg}))$ were selected.

\section{Statistics}

ANCOVA, t-tests and Wilcoxon tests were applied in the statistical analyses. Using ANCOVA, the follow-up value of 
each variable reviewed was used as response variable. The associated baseline value of the corresponding variable and the two-level factor, ASV or no ASV, were used as explanatory variables. The first step of the analysis was to fit the full model, consisting of different slopes and intercepts for each level of the factor. Subsequently, the model was simplified in order to find the minimal adequate model by removing all nonsignificant terms until a model with only significant terms was reached. Model simplifications were justified by the explanatory power of the model. The simpler model was preferred as long as it did not explain significantly less than the more complex model $(\alpha=0.05)$. Hence the full model with interaction was checked for significance and compared to the simplified model without interaction. In the case that the full model were preferred, which indicates a significant interaction, further analyses were not continued.

Significant interaction was found by models using the variables $V^{\prime} \mathrm{E} / V^{\prime} \mathrm{CO}_{2}$, oxygen pulse, $\mathrm{A}, \mathrm{E} / \mathrm{A}$ ratio, $\mathrm{E} / \mathrm{e}^{\prime}$ and $\mathrm{E}$. Unless the simpler model were preferred, the interaction could be neglected and it was checked whether the two-level factor was significant. For this purpose, the model without interaction was checked for significance and compared to a model without interaction and the two-level factor $(\alpha=0.05)$. Provided that the simpler model of these two were preferred, the twolevel factor (ASV or no ASV) is nonsignificant and the resulting model does not include the categorical variable. Whenever the model without interaction, consisting of a common slope and different intercepts, was preferred, the two-level factor is significant and this model is the minimal adequate model. Differences between the groups were compared using an unpaired t-test. Weight changes, NYHA class (noncategorical parameter, which could not be included in the ANCOVA analysis) and changes in sleep study results from baseline to follow-up were analysed using a paired t-test if the normality test (Kolmogorov-Smirnov) was passed, and with the help of the Wilcoxon test if the normality test was failed. A p-value of $<0.05$ was considered significant for all comparisons. Data are presented as mean \pm SD unless stated otherwise. Owing to missing observations, $<60$ individuals were used in the various analyses. Statistical analyses were performed using the open source software R-2.6.2 [19].

\section{RESULTS}

A total of 60 patients were included in the present study, all suffering from HFNEF and CSR and with an AHI of $>15$ events $\cdot h^{-1}$. Although 39 patients received ASV therapy, 21 formed the control group due to rejecting therapy for various reasons (fig. 1). The underlying cardiac disease in the treatment group was hypertensive heart disease in $16(41 \%)$ cases, coronary artery disease in $16(41 \%)$ and cardiomyopathies (six hypertrophic and one restrictive) in seven (18\%). In the control group, 12 (57\%) patients presented with coronary artery disease, five $(24 \%)$ with hypertensive heart disease and four (19\%) with cardiomyopathies (all hypertrophic). According to echocardiographic assessment, patients undergoing ASV therapy exhibited a pseudonormal left ventricular filling pattern in 20 (51\%) cases; an impaired relaxation filling pattern in $14(36 \%)$ and a restrictive filling pattern in five (13\%). In the control group, 10 $(48 \%)$ patients presented with a pseudonormal, 7 (33\%) with an impaired relaxation and four $(19 \%)$ with a restrictive filling pattern. Demographic and clinical data are given in table 1 . The group who did not receive ASV therapy presented with a higher $P$ LV,ED, whereas the treatment group showed larger left atrial diameters. Patients undergoing ASV therapy reattended the hospital $2.8 \pm 0.5$ times and patients in the control group $1.3 \pm 0.3$ times, mainly for planned follow-up investigations. Six patients in the therapy group and eight in the control group were readmitted to hospital for any intervention or acute worsening of cardiac status leading to any change in heart failure medication, and were thus considered as study dropouts (fig. 1). During the course of the study, there was no significant change in patients' weight, neither in the ASV therapy group $(89.9 \pm 17.0$ to $89.3 \pm 17.9 \mathrm{~kg} ; \mathrm{p}=0.33)$ nor in the control group $(90.7 \pm 15.3$ to $91.0 \pm 16.0 \mathrm{~kg} ; \mathrm{p}=0.45)$.

\section{Sleep study results}

Sleep study results at baseline are presented in table 1 . ASV therapy led to a significant reduction in AHI $(43.5 \pm 14.7$ to $3.5 \pm 1.7$ events $\left.\cdot \mathrm{h}^{-1} ; \mathrm{p}<0.001\right)$, longest apnoea $(32.3 \pm 24.7$ to $19.3 \pm 16.8 \mathrm{~s} ; \mathrm{p}<0.001)$ and hypopnoea $(37.9 \pm 10.6$ to $23.7 \pm$ $13.1 \mathrm{~s} ; \mathrm{p}<0.01)$, maximum desaturation $(82.8 \pm 4.8$ to $88.1 \pm$ $3.7 \%$; $<<0.01)$, percentage of study time at $<90 \%$ oxygen saturation $(7.6 \pm 12.8$ to $1.1 \pm 3.2 \% ; \mathrm{p}<0.01)$, arousal index $\left(30.7 \pm 6.4\right.$ to $17.5 \pm 8.8$ events $\left.\cdot h^{-1} ; \mathrm{p}<0.01\right)$ and mean oxygen desaturation $(5.6 \pm 2.0$ to $3.4 \pm 1.6 \% ; \mathrm{p}<0.01)$. Total sleep time $(359 \pm 23$ to $344 \pm 26 \mathrm{~min} ; \mathrm{p}=0.17)$ rapid eye movement sleep/ total sleep time $(13.1 \pm 8.1$ to $15.4 \pm 8.4 \% ; \mathrm{p}=0.10)$ and mean oxygen saturation $(92.5 \pm 2.3$ to $92.8 \pm 2.5 \% ; \mathrm{p}=0.32)$ remained unchanged. Device-based data analysis illustrated a mean usage of $>4 \mathrm{~h} \cdot$ day $^{-1}$ in $64.0 \pm 30.4 \%$ of all possible treatment nights, with a mean use of $5.3 \pm 2.1 \mathrm{~h} \cdot \mathrm{day}^{-1}$, an AHI for the entire treatment period of $4.2 \pm 4.5$ events $\cdot \mathrm{h}^{-1}$ and an apnoea index of $0.2 \pm 0.4$ events $\cdot h^{-1}$. Noncompliant patients presented with a mean usage of $>4 \mathrm{~h} \cdot \mathrm{day}^{-1}$ in $10.1 \pm 14.4 \%$ of all possible treatment nights, with a mean use of $0.8 \pm 1.4 \mathrm{~h} \cdot$ day $^{-1}$. In these patients, the AHI was $3.8 \pm 6.9$ events $\cdot h^{-1}$ and the apnoea index $0.2 \pm 0.8$ events $\cdot h^{-1}$.

\section{NYHA class}

There was a significant reduction in NYHA class in both the ASV treatment group $(2.4 \pm 0.6$ to $2.0 \pm 0.8 ; \mathrm{p}<0.001)$ and the control group $(2.5 \pm 0.5$ to $2.2 \pm 0.4 ; \mathrm{p}<0.01)$.

\section{NT-proBNP}

Reductions in NT-proBNP concentration were documented in ASV-treated patients and controls; however, these changes did not differ between the groups (table 2).

\section{Cardiopulmonary exercise testing}

The cardiopulmonary exercise testing results are presented in table 2. ASV therapy led to a significant increase in $V^{\prime} \mathrm{O}_{2}, \mathrm{AT}$, $V^{\prime} \mathrm{O}_{2}$,peak, predicted $V^{\prime} \mathrm{O}_{2}$,peak and oxygen pulse. $V^{\prime} \mathrm{E} / V^{\prime} \mathrm{CO}_{2}$ and exercise duration tended to improve without reaching a level of significance.

\section{Echocardiography}

ASV treatment led to a significant decrease in left atrial diameter and E/A, as well as a significant increase in A, $\mathrm{e}^{\prime}$ and $\mathrm{E} / \mathrm{e}^{\prime}$. Additional findings are presented in table 2 . 


\begin{tabular}{|c|c|c|c|c|}
\hline \multirow[t]{2}{*}{ TABLE 1} & \multicolumn{4}{|c|}{$\begin{array}{l}\text { Demographic and clinical data of the study } \\
\text { population }\end{array}$} \\
\hline & & ASV & Control & p-value \\
\hline \multicolumn{2}{|l|}{ Subjects $\mathrm{n}$} & 39 & 21 & \\
\hline \multicolumn{2}{|l|}{ Males } & $33(84.6)$ & $18(85.7)$ & 0.76 \\
\hline \multicolumn{2}{|l|}{ Age yrs } & $67.4 \pm 8.5$ & $69.7 \pm 7.9$ & 0.61 \\
\hline \multicolumn{2}{|l|}{ Weight kg } & $89.9 \pm 17.0$ & $90.7 \pm 15.3$ & 0.86 \\
\hline \multicolumn{2}{|l|}{ Height $\mathrm{cm}$} & $170.0 \pm 29.0$ & $174.1 \pm 8.7$ & 0.57 \\
\hline \multicolumn{2}{|l|}{ BMI $\mathbf{k g} \cdot \mathrm{m}^{-2}$} & $28.5 \pm 6.7$ & $29.8 \pm 4.2$ & 0.41 \\
\hline \multicolumn{2}{|l|}{ NYHA class } & $2.4 \pm 0.6$ & $2.5 \pm 0.5$ & 0.85 \\
\hline \multicolumn{2}{|c|}{ NT-proBNP pg $\cdot \mathrm{mL}^{-1}$} & $1480 \pm 1630$ & $1673 \pm 1965$ & 0.11 \\
\hline \multicolumn{2}{|c|}{$f_{c}$ at rest beats $\mathrm{min}^{-1}$} & $74.3 \pm 13.1$ & $71.1 \pm 8.2$ & 0.43 \\
\hline \multicolumn{2}{|c|}{ Hypertension } & $36(92.3)$ & $18(85.7)$ & 0.45 \\
\hline \multicolumn{2}{|l|}{ Diabetes } & $15(38.5)$ & $7(33.3)$ & 0.78 \\
\hline \multicolumn{2}{|c|}{ Atrial fibrillation } & $9(23.1)$ & $4(19.0)$ & 0.38 \\
\hline \multicolumn{2}{|c|}{ Cerebrovascular disease } & $5(12.8)$ & $3(14.2)$ & 0.49 \\
\hline \multicolumn{5}{|l|}{ Medication } \\
\hline \multicolumn{2}{|c|}{$\beta$-Blockers } & $33(84.6)$ & $19(90.4)$ & 0.51 \\
\hline \multicolumn{2}{|c|}{ ACE/AT ${ }_{1}$ inhibitors } & 36 (92.3) & $18(85.7)$ & 0.45 \\
\hline Calcium c & annel blockers & $15(38.5)$ & $11(52.3)$ & 0.20 \\
\hline Nitrates & & $11(28.2)$ & $5(23.8)$ & 0.68 \\
\hline Digitalis $\mathrm{g}$ & cosides & $6(15.4)$ & $3(14.2)$ & 0.88 \\
\hline Diuretics & & $29(74.3)$ & $19(90.4)$ & 0.13 \\
\hline Blood gas & alysis & & & \\
\hline$P_{\mathrm{c}, \mathrm{CO}_{2}} \mathrm{mn}$ & & $35.9 \pm 3.3$ & $35.7 \pm 4.0$ & 0.44 \\
\hline$P_{\mathrm{c}, \mathrm{O}_{2}} \mathrm{mml}$ & & $76.7 \pm 8.4$ & $74.6 \pm 10.7$ & 0.44 \\
\hline Sleep stud & esults & & & \\
\hline Total slee & ime min & $359 \pm 23$ & $345 \pm 19$ & 0.31 \\
\hline REM/total & eep time \% & $13.1 \pm 8.1$ & $12.7 \pm 7.6$ & 0.54 \\
\hline $\mathrm{AHI}$ event & & $43.5 \pm 14.7$ & $39.8 \pm 20.9$ & 0.41 \\
\hline Mean $S p, C$ & & $92.5 \pm 2.3$ & $92.0 \pm 2.5$ & 0.42 \\
\hline $\mathrm{Sp}, \mathrm{O}_{2}, \min 9$ & & $82.8 \pm 4.8$ & $83.2 \pm 4.4$ & 0.71 \\
\hline Mean des & uration \% & $5.6 \pm 2.0$ & $5.3 \pm 1.3$ & 0.66 \\
\hline Longest a & noea s & $32.3 \pm 24.7$ & $29.4 \pm 11.5$ & 0.61 \\
\hline Longest $\mathrm{h}$ & opnoea s & $37.9 \pm 10.6$ & $42.5 \pm 18.1$ & 0.23 \\
\hline Study time & at $\mathrm{Sp}, \mathrm{O}_{2}$ of $<90 \% \%$ & $7.6 \pm 12.8$ & $7.1 \pm 13.1$ & 0.43 \\
\hline Arousal in & & $30.7 \pm 6.4$ & $29.9 \pm 7.8$ & 0.33 \\
\hline Invasive ha & modynamics & & & \\
\hline $\bar{P}$ pa $\mathrm{mmH}$ & & $33.5 \pm 8.9$ & $29.5 \pm 6.5$ & 0.12 \\
\hline Ppow mml & & $22.7 \pm 4.5$ & $22.0 \pm 3.7$ & 0.64 \\
\hline PLV,ED mn & & $23.5 \pm 5.4$ & $25.4 \pm 9.3$ & 0.046 \\
\hline Pulmonary & Inction testing & & & \\
\hline FVC L & & $3.3 \pm 0.9$ & $3.1 \pm 0.9$ & 0.68 \\
\hline FEV 1 L & & $2.9 \pm 0.9$ & $2.7 \pm 0.8$ & 0.55 \\
\hline $\mathrm{FEV}_{1} / \mathrm{FVC}$ & & $87.9 \pm 6.3$ & $85.3 \pm 4.9$ & 0.63 \\
\hline TLC L & & $6.4 \pm 1.9$ & $6.5 \pm 1.3$ & 0.83 \\
\hline TLC \% pre & & $90.1 \pm 20.6$ & $95.8 \pm 13.9$ & 0.46 \\
\hline TGV L & & $3.5 \pm 1.1$ & $3.8 \pm 1.1$ & 0.56 \\
\hline TGV \% pr & & $93.8 \pm 29.4$ & $98.6 \pm 24.4$ & 0.53 \\
\hline$K \mathrm{CO}(\mathrm{Hb})$ & $\mathrm{mol} \cdot \mathrm{kPa}^{-1} \cdot \mathrm{min}^{-1} \cdot \mathrm{L}^{-1}$ & $1.3 \pm 0.5$ & $1.3 \pm 0.4$ & 0.79 \\
\hline $\mathrm{KCO}(\mathrm{Hb})$ & pred & $102.6 \pm 40.1$ & $99.8 \pm 26.3$ & 0.85 \\
\hline Echocardio & raphy & & & \\
\hline$E m \cdot s^{-1}$ & & $0.8 \pm 0.3$ & $0.8 \pm 0.3$ & 0.88 \\
\hline$A m \cdot s^{-1}$ & & $0.7 \pm 0.2$ & $0.6 \pm 0.3$ & 0.30 \\
\hline DT ms & & $215 \pm 78$ & $215 \pm 78$ & 0.80 \\
\hline LAD mm & & $52.0 \pm 5.5$ & $48.2 \pm 6.1$ & 0.02 \\
\hline$E / A$ & & $1.4 \pm 1.0$ & $1.4 \pm 1.1$ & 0.36 \\
\hline$e^{\prime} m \cdot s^{-1}$ & & $3.8 \pm 1.4$ & $4.5 \pm 1.6$ & 0.08 \\
\hline$E / e^{\prime}$ & & $22.2 \pm 9.7$ & $19.2 \pm 7.8$ & 0.11 \\
\hline
\end{tabular}

\begin{tabular}{|c|c|c|c|}
\hline & ASV & Control & p-value \\
\hline \multicolumn{4}{|c|}{ Cardiopulmonary exercise testing } \\
\hline$V^{\prime} \mathrm{O}_{2}, \mathrm{AT} \mathrm{mL} \cdot \mathrm{min}^{-1} \cdot \mathrm{kg}^{-1}$ & $12.9 \pm 3.6$ & $14.1 \pm 3.9$ & 0.29 \\
\hline$V^{\prime} \mathrm{O}_{2}$, peak $\mathrm{mL} \cdot \mathrm{min}^{-1} \cdot \mathrm{kg}^{-1}$ & $14.9 \pm 4.7$ & $16.3 \pm 4.3$ & 0.17 \\
\hline $\mathrm{V}^{\prime} \mathrm{O}_{2}$,peak $\%$ pred & $64.8 \pm 18.3$ & $75.6 \pm 17.6$ & 0.10 \\
\hline Workload W & $94.7 \pm 37.9$ & $87.6 \pm 37.0$ & 0.59 \\
\hline Duration min & $10.4 \pm 3.0$ & $9.1 \pm 3.0$ & 0.21 \\
\hline$V^{\prime} E / V^{\prime} \mathrm{CO}_{2}$ & $33.0 \pm 5.2$ & $35.3 \pm 4.9$ & 0.18 \\
\hline HRR beats $\cdot \min ^{-1}$ & $47.5 \pm 28.4$ & $52.4 \pm 22.6$ & 0.54 \\
\hline Oxygen pulse $\mathrm{mL} \cdot$ beat $^{-1}$ & $13.6 \pm 3.1$ & $13.7 \pm 3.1$ & 0.34 \\
\hline Oxygen pulse \% pred & $78.6 \pm 23.0$ & $88.1 \pm 18.0$ & 0.51 \\
\hline
\end{tabular}

Data are presented as mean \pm SD or $n(\%)$ unless otherwise indicated. ASV: adaptive servoventilation; BMI: body mass index; NYHA: New York Heart Association; NT-proBNP: N-terminal-pro-brain natriuretic peptide; $f_{c}$ : cardiac frequency; $\mathrm{ACE}$ : angiotensin-converting enzyme; $\mathrm{AT}_{1}$ : angiotensin II receptor type $1 ; P_{\mathrm{c}, \mathrm{CO}_{2}}$ : capillary carbon dioxide tension; $P_{\mathrm{c}, \mathrm{O}_{2}}$ : capillary oxygen tension; REM: rapid eye movement; $\mathrm{AHI}$ : apnoea/hypopnoea index; $\mathrm{Sp}, \mathrm{O}_{2}$ : arterial oxygen saturation measured by pulse oximetry; $\mathrm{Sp}, \mathrm{O}_{2}$, min: minimal $\mathrm{Sp}, \mathrm{O}_{2}$; $\bar{P}_{\text {pa: }}$ mean pulmonary arterial pressure; $P_{\text {pcw: }}$ pulmonary capillary wedge pressure; PLV,ED: end-diastolic left ventricular pressure; FVC: forced vital capacity; \% pred: \% predicted; FEV1: forced expiratory volume in $1 \mathrm{~s}$; TLC: total lung capacity; TGV: thoracic gas volume; KCO: transfer coefficient of the lung for carbon monoxide; $\mathrm{Hb}$ : haemoglobin; E: peak early Doppler mitral inflow velocity; A: peak atrial Doppler mitral inflow velocity; DT: deceleration time; LAD: left atrial diameter; e': mean early diastolic lengthening velocity; $V^{\prime} \mathrm{O}_{2}, \mathrm{AT}$ : oxygen consumption at the aerobic-anaerobic threshold; $V^{\prime} \mathrm{O}_{2}$,peak: peak oxygen consumption; $V^{\prime} E$ : minute ventilation; $V^{\prime} \mathrm{CO}_{2}$ : carbon dioxide production; HRR: heart rate recovery

\section{DISCUSSION}

This is the first study evaluating the effect of ASV in patients with HFNEF and moderate-to-severe CSR. The main finding of the present study is that ASV not only improves CSR, with a reduction in $\mathrm{AHI}$ and other sleep study parameters, but also has a positive effect on cardiopulmonary exercise capacity, left atrial diameter and echocardiographic measures of diastolic ventricular performance in comparison to an untreated control group.

SDB is common in patients with HFNEF [4]. Focusing on obstructive sleep apnoea in HFNEF, ARIAS et al. [9] investigated 15 patients, 11 of whom presented with an impaired relaxation filling pattern and four with a pseudonormal filling pattern. After 12 weeks of nocturnal application of CPAP, in contrast to previously applied sham CPAP, echocardiographic parameters of diastolic dysfunction improved, suggesting that CPAP therapy could prevent the progression of diastolic abnormalities in these patients, and might reverse alterations. Similar results were presented in three other studies, all observing an improvement in various parameters of diastolic dysfunction [10-12].

As described previously, CSR arises from a different pathophysiological mechanism: enhanced pulmonary capillary wedge pressure leads to stimulation of pulmonary vagal irritant receptors (J-receptors) and enhances the chemosensitivity of 


\begin{tabular}{|c|c|c|c|c|}
\hline \multirow[t]{2}{*}{ TABLE 2} & \multicolumn{4}{|c|}{$\begin{array}{l}\text { Follow-up results for N-terminal-pro-brain } \\
\text { natriuretic peptide (NT-proBNP), } \\
\text { echocardiography and standardised } \\
\text { cardiopulmonary exercise testing }\end{array}$} \\
\hline & & ASV & Control & p-value \\
\hline \multicolumn{2}{|c|}{$f_{c}$ at rest beats $\cdot \min ^{-1}$} & $68.1 \pm 11.3$ & $67.8 \pm 7.5$ & 0.92 \\
\hline \multicolumn{2}{|c|}{ NT-proBNP pg $\cdot \mathrm{mL}^{-1}$} & $740 \pm 1110$ & $1480 \pm 890$ & 0.10 \\
\hline \multicolumn{5}{|c|}{ Echocardiography } \\
\hline \multicolumn{2}{|c|}{$E m \cdot s^{-1}$} & $0.7 \pm 0.3$ & $0.8 \pm 0.3$ & 0.73 \\
\hline \multicolumn{2}{|l|}{$A \mathrm{~m} \cdot \mathrm{s}^{-1}$} & $0.8 \pm 0.2$ & $0.7 \pm 0.2$ & 0.04 \\
\hline \multicolumn{2}{|l|}{ DT ms } & $229 \pm 53$ & $235 \pm 91$ & 0.72 \\
\hline \multicolumn{2}{|l|}{ LAD mm } & $49.8 \pm 7.4$ & $51.1 \pm 5.8$ & $<0.01$ \\
\hline \multicolumn{2}{|l|}{$E / A$} & $1.1 \pm 0.6$ & $1.2 \pm 0.6$ & $<0.01$ \\
\hline \multicolumn{2}{|l|}{$e^{\prime} m \cdot s^{-1}$} & $4.3 \pm 1.0$ & $4.3 \pm 1.5$ & $<0.01$ \\
\hline \multicolumn{2}{|l|}{ E/e' } & $17.9 \pm 7.0$ & $21.7 \pm 14.7$ & 0.03 \\
\hline \multicolumn{5}{|c|}{ Cardiopulmonary exercise testing } \\
\hline \multicolumn{2}{|c|}{$V^{\prime} \mathrm{O}_{2}, \mathrm{AT} \mathrm{mL} \cdot \mathrm{min}^{-1} \cdot \mathrm{kg}^{-1}$} & $15.7 \pm 4.3$ & $12.7 \pm 2.8$ & 0.01 \\
\hline \multicolumn{2}{|c|}{$V^{\prime} \mathrm{O}_{2}$, peak $\mathrm{mL} \cdot \mathrm{min}^{-1} \cdot \mathrm{kg}^{-1}$} & $17.8 \pm 5.5$ & $15.2 \pm 4.1$ & $<0.01$ \\
\hline \multicolumn{2}{|c|}{$V^{\prime} \mathrm{O}_{2}$,peak \% pred } & $78.4 \pm 22.2$ & $69.1 \pm 19.7$ & $<0.01$ \\
\hline \multicolumn{2}{|c|}{ Workload W } & $102.1 \pm 36.8$ & $95.0 \pm 38.4$ & 0.61 \\
\hline \multicolumn{2}{|c|}{ Duration min } & $11.1 \pm 3.0$ & $8.9 \pm 2.5$ & 0.06 \\
\hline \multicolumn{2}{|l|}{$V^{\prime} E / V^{\prime} \mathrm{CO}_{2}$} & $31.1 \pm 4.9$ & $34.1 \pm 5.6$ & 0.07 \\
\hline \multicolumn{2}{|c|}{ HRR beats $\cdot \min ^{-1}$} & $52.7 \pm 24.3$ & $58.1 \pm 19.8$ & 0.25 \\
\hline \multicolumn{2}{|c|}{ Oxygen pulse $\mathrm{mL} \cdot$ beat $^{-1}$} & $15.8 \pm 3.6$ & $13.5 \pm 3.7$ & $<0.01$ \\
\hline \multicolumn{2}{|c|}{ Oxygen pulse \% pred } & $97.8 \pm 29.0$ & $84.1 \pm 23.8$ & 0.13 \\
\hline
\end{tabular}

Data are presented as mean $\pm S D$, unless otherwise stated. ASV: adaptive servoventilation; fc: cardiac frequency; E: peak early Doppler mitral inflow velocity; A: peak atrial Doppler mitral inflow velocity; DT: deceleration time; LAD: left atrial diameter; $e^{\prime}$ : mean early diastolic lengthening velocity; $V^{\prime} \mathrm{O}_{2}, \mathrm{AT}$ : oxygen consumption at the aerobic-anaerobic threshold; $V^{\prime} \mathrm{O}_{2}$,peak: peak oxygen consumption; $V^{\prime} E$ : minute ventilation; $V^{\prime} \mathrm{CO}_{2}$ : carbon dioxide production; HRR: heart rate recovery.

central carbon dioxide receptors, resulting in hyperventilation. This, in turn, leads to a consecutive decrease in $P_{\mathrm{c}, \mathrm{O}_{2}}$ below the apnoea threshold with consecutive apnoeas $[2,3,20]$.

In patients with HFNEF and CSR, the effects of CPAP therapy have not yet been investigated. The Canadian Continuous Positive Airway Pressure for Patients with Central Sleep Apnea and Heart Failure (CANPAP) trial investigated 258 heart failure patients with reduced left ventricular ejection fraction and CSR [21]. Of these, 128 were randomised to receive CPAP therapy, whereas the remaining 130 did not. The authors could not find a superiority of the treatment group with respect to the primary end-point of survival after 24 months. A post-hoc analysis highlighted the major problem of this study, namely a decrease in AHI from $40 \pm 16$ by only $21 \pm 16$ events $\cdot h^{-1}$; a prognostic benefit could only be demonstrated for patients with an AHI of $<15$ events $\cdot h^{-1}$ [22].

ASV offers ventilatory support with reduced pressure in phases of normo- and hyperventilation and does not potentiate loss of carbon dioxide as a trigger for central apnoea. Besides effectively attenuating hypopnoea and apnoea events in HFREF, details of positive effects on symptoms, neurohormonal activation, left ventricular functional parameters and cardiopulmonary exercise tolerance have recently been published [5-8, 23].

By analogy to patients with HFREF and CSR, the current study presents similar findings in those with a normal left ventricular ejection fraction. Explanations for this are rarely investigated, however. Nevertheless it has been shown that the SDB runs parallel with several systemic changes. Hypoxaemia in patients with obstructive sleep apnoea leads to vast sympathetic activation [24]. Even though hypoxaemic events are less extensive in patients with CSR, a similar mechanism is plausible in CSR. In addition, CSR occurs with periods of hyperventilation that are probably also accompanied by excessive sympathetic activation [25]. The consequences that emerge from this are, for example, enhanced blood pressure [26], activation of the renin-angiotensin-aldosterone system (RAAS) [27] and increased levels of vasoconstrictive factors, such as circulating noradrenalin and endothelin [28, 29]. This, again, may stimulate fibrogenesis with increased myocardial collagen turnover [30] and a shift in protein expression (upregulated expression of procollagen types I and III, matrix metalloproteinase and a less compliant isoform of titin) [30-32], resulting in increased myocardial stiffness and increased matrix degradation. Reducing these stress factors may result in positive (reverse-) remodelling analogous to medical inhibition of the RAAS. Furthermore, vasoconstriction (as well as hypertension) itself increases afterload, $P$ LV,ED and consecutive structural myocardial changes [33]. Another pathophysiological explanation might be inflammatory reaction induced by the apnoea and/or hyperventilation. Proven in obstructive sleep apnoea patients, this is in agreement with the increased serum levels of cytokines and acute-phase proteins, such as amyloid A, which, itself, could predispose to diastolic dysfunction [34].

Controlling CSR-induced systemic consequences by ASV could be the key to the success of this nonmedical therapeutic approach.

\section{Potential limitations}

There are some potential limitations to the present study. Treatment allocation was not randomised and blinded to patients and physicians. Even though the groups were similar with respect to measured baseline variables, the groups may differ in factors that cannot be measured due to the lack of randomisation. In addition, the lacking randomisation may have caused a selection bias: patients who comply with ASV therapy may also present with superior compliance to the rest of their heart failure treatment. In a recent study, for instance, it was shown that disease management programmes, as one method of improving patients' therapy compliance, lead to superior survival in systolic heart failure [35]. Another possible limitation is the echocardiographic evaluation of $\mathrm{e}^{\prime}$ by speckle tracking. Even though the $\mathrm{e}^{\prime}$ derived from speckle tracking shows significantly lower velocities than that from tissue Doppler, the speckle-tracking-derived $\mathrm{E} / \mathrm{e}^{\prime}$ is at least equal to the tissue Doppler $\mathrm{E} / \mathrm{e}^{\prime}$ for the prediction of elevated left ventricular filling pressures [36]. In addition, intraindividual changes that were independent of the evaluation method were focused on. Finally, the study group consisted of patients with HFNEF due to different aetiologies. Owing to this small number of patients, it was not possible to perform a subgroup analysis to clarify the impact of different aetiologies of HFNEF on outcome. 


\section{Summary}

In patients with HFNEF and CSR, ASV not only improves CSR, with a reduction in $\mathrm{AHI}$ and other sleep study parameters, but also has a positive effect on cardiopulmonary exercise capacity and echocardiographic parameters of diastolic function in comparison to an untreated group. This effect may be mediated by eliminating the adverse CSR-associated systemic consequences by controlling nocturnal CSR with ASV. Nevertheless end-point-triggered, randomised and blinded studies are necessary for further evaluation of this therapeutic approach.

\section{STATEMENT OF INTEREST}

Statements of interest for T. Bitter and O. Oldenburg can be found at www.erj.ersjournals.com/misc/statements.dtl

\section{REFERENCES}

1 Senni M, Tribouilloy CM, Rodeheffer RJ, et al. Congestive heart failure in the community: trends in incidence and survival in a 10year period. Arch Intern Med 1999; 159: 29-34.

2 Oldenburg O, Bitter T, Wiemer M, et al. Pulmonary capillary wedge pressure and pulmonary arterial pressure in heart failure patients with sleep-disordered breathing. Sleep Med 2009; 10: 726-730.

3 Solin $\mathrm{P}$, Bergin $\mathrm{P}$, Richardson $\mathrm{M}$, et al. Influence of pulmonary capillary wedge pressure on central apnea in heart failure. Circulation 1999; 99: 1574-1579.

4 Bitter T, Prinz C, Faber L, et al. Sleep-disordered breathing in heart failure with normal left ventricular ejection fraction. Eur J Heart Fail 2009; 11: 602-608.

5 Teschler H, Döhring J, Wang YM, et al. Adaptive pressure support servo-ventilation: a novel treatment for Cheyne-Stokes respiration in heart failure. Am J Respir Crit Care Med 2001; 164: 614-619.

6 Pepperell JTC, Maskell NA, Jones DR, et al. A randomized controlled trial of adaptive ventilation for Cheyne-Stokes breathing in heart failure. Am J Respir Crit Care Med 2003; 168: 1109-1114.

7 Fietze I, Blau A, Glos A, et al. Bi-level positive pressure ventilation in patients with heart failure and Cheyne-Stokes respiration. Sleep Med 2008; 9: 652-659.

8 Philippe C, Stoica-Herman M, Drouot X, et al. Compliance with and effectiveness of adaptive servoventilation versus continuous positive airway pressure in the treatment of Cheyne-Stokes respiration in heart failure over a six month period. Heart 2006; 92: 337-342.

9 Arias MA, García-Río F, Alonso-Fernández A, et al. Obstructive sleep apnoea syndrome affects left ventricular diastolic function: effects of nasal continuous positive airway pressure in men. Circulation 2005; 112: 375-383.

10 Alchanatis M, Tourkohoriti G, Kosmas EN, et al. Evidence for left ventricular dysfunction in patients with obstructive sleep apnoea syndrome. Eur Respir J 2002; 20: 1239-1245.

11 Shivalkar B, Van de Heyning C, Kerremans M, et al. Obstructive sleep apnoea syndrome: more insights on structural and functional cardiac alterations, and the effects of treatment with continuous positive airway pressure. J Am Coll Cardiol 2006; 47: 1433-1439.

12 Alchanatis M, Paradellis G, Pini H, et al. Left ventricular function in patients with obstructive sleep apnoea syndrome before and after treatment with nasal continuous positive airway pressure. Respiration 2000; 67: 367-371.

13 Paulus WJ, Tschöpe C, Sanderson JE, et al. How to diagnose diastolic heart failure: a consensus statement on the diagnosis of heart failure with normal left ventricular ejection fraction by the
Heart Failure and Echocardiography Associations of the European Society of Cardiology. Eur Heart J 2007; 28: 2539-2550.

14 Dickstein K, Cohen-Solal A, Filippatos G, et al. ESC guidelines for the diagnosis and treatment of acute and chronic heart failure 2008. The Task Force for the diagnosis and treatment of acute and chronic heart failure 2008 of the European Society of Cardiology. Developed in collaboration with the Heart Failure Association of the ESC (HFA) and endorsed by the European Society of Intensive Care Medicine (ESICM). Eur J Heart Fail 2008; 10: 933-989.

15 Rechtschaffen A, Kales A. A Manual of Standardized Terminology, Techniques, and Scoring System for Sleep Stages of Human Subjects. Los Angeles, Brain Information Service, 1968.

16 Iber C, Ancoli-Israel S, Chesson AL Jr, et al. The AASM Manual for the Scoring of Sleep and Associated Events: Rules, Terminology and Technical Specifications. Westchester, American Academy of Sleep Medicine, 2007.

17 Kasai T, Narui K, Dohi T, et al. Prognosis of patients with heart failure and obstructive sleep apnea treated with continuous positive airway pressure. Chest 2008; 133: 690-696.

18 Cheitlin MD, Armstrong WF, Aurigemma GP, et al. ACC/AHA/ ASE Guideline Update for the Clinical Application of Echocardiography: Summary Article: a report of the American College of Cardiology/American Heart Association Task Force on Practice Guidelines (ACC/AHA/ASE Committee to update the 1997 guidelines for the clinical application of echocardiography). J Am Soc Echocardiogr 2003; 16: 1091-1110.

19 R Foundation. The R Project for Statistical Computing. www.rproject.org Date last updated: October 15, 2009. Date last accessed: October 15, 2009

20 Javaheri S. A mechanism of central sleep apnoea in patients with heart failure. N Engl J Med 1999; 341: 949-954

21 Bradley TD, Logan AG, Kimoff RJ, et al. Continuous positive airway pressure for central sleep apnea and heart failure. $N$ Engl J Med 2005; 353: 2025-2033.

22 Arzt M, Floras JS, Logan AG, et al. Suppression of central sleep apnea by continuous positive airway pressure and transplant-free survival in heart failure: a post hoc analysis of the Canadian Continuous Positive Airway Pressure for Patients with Central Sleep Apnea and Heart Failure Trial (CANPAP). Circulation 2007; 115: 3173-3180.

23 Oldenburg O, Schmidt A, Lamp B, et al. Adaptive servoventilation improves cardiac function in patients with chronic heart failure and Cheyne-Stokes respiration. Eur J Heart Fail 2008; 10: 581-586.

24 Imadojemu VA, Mawji Z, Kunselman A, et al. Sympathetic chemoreflex responses in obstructive sleep apnea and effects of continuous positive airway pressure therapy. Chest 2007; 131: 1406-1413.

25 Van De Borne P, Mezzetti S, Montano N, et al. Hyperventilation alters arterial baroreflex control of heart rate and muscle sympathetic nerve activity. Am J Physiol Heart Circ Physiol 2000; 279: 536-541.

26 Peppard PE, Young T, Palta M, et al. Prospective study of the association between sleep-disordered breathing and hypertension. N Engl J Med 2000; 342: 1378-1384.

27 Calhoun DA, Nishizaka MK, Zaman MA, et al. Aldosterone excretion among subjects with resistant hypertension and symptoms of sleep apnea. Chest 2004; 125: 112-117.

28 Dimsdale JE, Ziegler MG, Ancoli-Israel S, et al. The effect of sleep apnea on plasma and urinary catecholamines. Sleep 1995; 18: 377-381.

29 Phillips BG, Narkiewicz K, Pesek CA, et al. Effects of obstructive sleep apnea on endothelin-1 and blood pressure. J Hypertens 1999; 17: 61-66.

30 Martos R, Baugh J, Ledwidge M, et al. Diastolic heart failure: evidence of increased myocardial collagen turnover linked to diastolic dysfunction. Circulation 2007; 115: 888-895.

31 Spinale FG, Coker ML, Heung LJ, et al. A matrix metalloproteinase induction/activation system exists in the human left ventricular 
myocardium and is upregulated in heart failure. Circulation 2000; 102: 1944-1949.

32 van Heerebeek L, Borbély A, Niessen HW, et al. Myocardial structure and function differ in systolic and diastolic heart failure. Circulation 2006; 113: 1966-1973.

33 Piper C, Schultheiss HP, Akdemir D, et al. Remodeling of the cardiac extracellular matrix differs between volume- and pressureoverloaded ventricles and is specific for each heart valve lesion. J Heart Valve Dis 2003; 12: 592-600.
34 Svatikova A, Wolk R, Shamsuzzaman AS, et al. Serum amyloid A in obstructive sleep apnea. Circulation 2003; 108: 1451-1454.

35 Galbreath AD, Krasuski R, Smith B, et al. Long-term healthcare and cost outcomes of disease management in a large, randomized, community-based population with heart failure. Circulation 2004; 110: 3518-3526.

$36 \mathrm{Ng} \mathrm{AC}$, Tran DT, Newman M, et al. Comparison of myocardial tissue velocities measured by two-dimensional speckle tracking and tissue Doppler imaging. Am J Cardiol 2008; 102: 784-789. 